\title{
Experimental study of aero-thermal heat sink performances subjected to impinging air flow
}

\author{
Abdelillah A. Belarbi ${ }^{1 *}$, M'hamed Beriache $^{1}$, Ahmed Bettahar $^{2}$ \\ ${ }^{1}$ Laboratoire de Rhéologie et mécanique, Department of Mechanical Engineering, Faculty of Technology, \\ University Hassiba Benbouali of Chlef, 02000, Algeria \\ ${ }^{2}$ Laboratoire de Contrôles, Essais, Mesures et Simulations Mécaniques' Department of Mechanical Engineering, \\ Faculty of Technology, University Hassiba Benbouali of Chlef, 02000, Algeria
}

Corresponding Author Email: a.belarbi@univ-chlef.dz

https://doi.org/10.18280/ijht.360420

Received: 20 July 2018

Accepted: 24 December 2018

\section{Keywords:}

heat sink, impinging air jet, cooling, case temperature, thermal resistance, pressure drop

\begin{abstract}
In this study, experimental investigation of thermal and aerodynamic performances of a rectangular mini-channel heat sink subjected to an impinging air jet was carried out with the aim to improve the cooling performance of personal computer CPUs. The influence of the impinging distance on the velocity profile, the pressure drop, the case temperature, the thermal resistance, and the heat transfer coefficient are studied. Moreover, the effect of the positioning of the microprocessor (heat source) on the thermal performance was investigated. The results show a ratio "height jet/diameter" $\mathrm{Y} / \mathrm{D}=0.606$ offer a better cooling, and a longitudinal displacement of the heat source (central processor unit) $10 \mathrm{~mm}$ from the original position (center) improve the cooling performance. The enhancement rate was in a range of $10 \%$ compared to the initial position (central position before shifting the source).
\end{abstract}

\section{INTRODUCTION}

Recent advances in electronics industries have resulted in an abrupt increase in power dissipation which has resulted in severe operating constraints, particularly for desktop microprocessors (CPUs). In order to function correctly, the microprocessor must have a case temperature less than an operating limit specified by the manufacturer.

Excessive overheating degrades CPU performance, reduces CPU life, and can cause failure. The study of the thermal behaviour of the CPU will therefore help to predict its reliability, its lifetime and the evolution of its performance over time. The need to improve the cooling techniques of highpower CPUs has widened the scope of the research on heat transfer at the latter, in particular on the maximum case temperature beyond which the component is destroyed.

Without effective heat transfer, excessive temperatures can make the operating performance of these components unstable, potentially reducing their lifetime by causing them to be damaged. Thus, the major challenge in the design of electronic components is to improve the efficiency of their heat transfer [1]. To do this, an effective cooling system must be designed to evacuate the amount of heat generated during the operation of the computer. This, in order to maintain their stability and reliability. The heat sink undergoing an impact air jet is the most widely used means of cooling electronic components because of its favorable unit cost, weight and reliability. The efficiency of these heat dissipation devices is imperative in their design, with a view to optimizing the cooling of the circuits to which they are connected [2]. Many researchers have studied the thermal and hydrodynamic characteristics of different heat sinks subjected to an impacting jet of air. Brignoni, L.A. and Col. [3] and El-Sheikh, H.A. and Col. [4] experimentally studied the heat transfer enhancement of squared pin- fins, subjected to a confined jet of air impinging for different Reynolds numbers and a fixed jet height. They have obtained that the heat transfer coefficient increases when the diameter of the jet decreases under a fixed air flow rate. This parameter is improved by 2.4 to 9.2 times more than that obtained with a plate fin heat sink. As for Maveety, J.G. and Col. [5-6], they carried out experimental and numerical studies on the performance of pin-fin heat sink, cooled by an impingement air jet. They have shown that geometry, air jet height and Reynolds number have a significant influence on the performance of heat sinks. In another study, Biber, C.R. and Col. [7] and Sathe S.B. and Col. Have described the process of optimizing a parallel fins heat sink associated with a fan for cooling electronic components. The parameters taken into account are the thickness of the fin, its height and its density as well as the number of fins. They draw the following conclusions: the sensitivity to the number of fins decreases as the fin height increases with a wider inter-fin space, which would be more suitable for a smaller pressure drop compared to narrow space inter-fin. Duan, Z.P. and Col. [9] studied the optimization of the performance of a plate fin heat sink under a rectangular impinging jet. The results showed that by cutting the fins located under the impact zone; this reduced the pressure drop without affecting the heat transfer.

Duan, Z.P. and Col. [10] and Muzychka, Y.S. [11] carried out a series of experiments on the thermal and aerodynamic performances of four plate fin heat sinks subjected to an impinging air jet in order to study the influence of the jet width, inter-fin spacing, the height of the fins and the flow velocity on the pressure drop and on the thermal resistance. Hung-Yi, L. and Cil. [12-13], have experimentally studied the thermal and aerodynamic performances of plate fin heat sink, subjected to confined air jet cooling. They found that at a specific Reynolds number, corresponds to an adequate blowing distance, giving the lowest thermal resistance. They obtained that the blowing 
distance increases with the Reynolds to a ratio between the impact distance and the jet diameter, $\mathrm{Y} / \mathrm{D}=20$, where it reaches a minimum value. Beyond the value of the ratio $\mathrm{Y} / \mathrm{D}=20$, the thermal resistance increases with a smaller fin height effect than the Reynolds number of the impinging jet. Dong-Kwon, K. et al. [14] carried out an experimental study by comparing the thermal performance of the plate fin heat sink with those of the pin-fin heat sink, subjected to impinging air jet. Experimental investigations were carried out for different flow rates and channel widths. It is found that plate fin heat sinks exhibit the lowest thermal resistance when the power dissipated is large and the length of the heat sink is small. Diani, A, and Col. [15], have developed a numerical model on the thermal and aerodynamic performances of a plate fin heat sink, which they were able to validate by experimental measurements carried out on the same heat sink model. The experiments were carried out by varying the mass flow of air for two different heat fluxes. They find that the overall heat transfer coefficient increases with the flow rate while the temperature at the heat sink wall decreases. Moreover, the flow rate and heat transfer characteristics of a plate fin heat sink cooled by a rectangular impinging jet for different jet widths were studied experimentally and numerically by Mesalhy, OM and El-Sayed, MM [16]. The study was carried out for several fins at different heights, under a turbulent jet stream. The results showed that the use of a narrow jet provides better dissipation of heat or even better cooling for heat sinks with a minimum number of short fins. In the literature, other researches have been developed in the aim to determine the average coefficient of heat transfer [17-18].

In light of the above, a limited number of researches exists in the literature to understand the performance of heat sinks under impinging air cooling, particularly for the plate fin heat sinks due to the complexity of the thermal and aerodynamic characteristics. It can be said that the domain is still virgin and needs to be even better explored. The aim of this research is to carry out an experimental study in order to improve the thermal and aerodynamic performance of a plate fin heat sink with rectangular mini-channels subjected to an impinging air jet coming from an axial fan for cooling desktop central processing unit (CPU). The influence of the height of the cooling fan and the positioning of the heat source under the heat sink on its thermal and aerodynamic performances are studied and discussed in order to optimize the cooling system.

\section{Experimental equipment}

The experimental test bench, shown in FIG. 1, consists essentially of an impinging air jet system, a heat sink (see FIG. 2 ) and devices for measuring the flow velocity, the pressure difference and the temperatures. The impact air jet system (1) consists of an axial fan 70x70x15 mm, type 12VDC 0.7A, delivering an impinging air of $42 \mathrm{~m}^{3} / \mathrm{h}$ with a jet diameter $\mathrm{D}=$ $66 \mathrm{~mm}$, the motor of which is powered by a DC voltage source (2). The speed of the fan varies with the supply voltage. The air flow is routed from the fan to the heat sink along a Plexiglas duct (3).

The heat sink (4) with rectangular mini-channel plate fin is made of pure extruded aluminum (FIG. 2), by virtue of its low density $\rho=2702 \mathrm{~kg} / \mathrm{m}^{3}$ and its high thermal conductivity, In the order of $237 \mathrm{Wm}^{-1} \mathrm{~K}^{-1}$ [19]. Its dimensions are shown in Table 1 below.

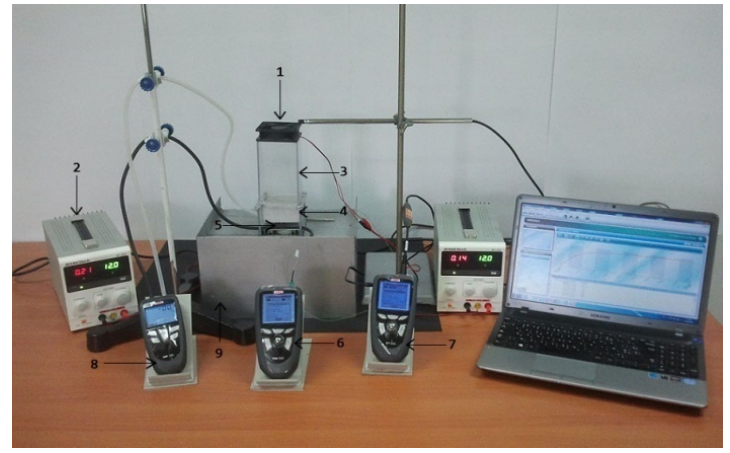

Figure 1. Experimental rig

Table 1. Heat sink dimensions

\begin{tabular}{c|c}
\hline $\mathrm{N}$ & 27 \\
\hline $\mathrm{W}(\mathrm{mm})$ & 66 \\
\hline $\mathrm{ha}(\mathrm{mm})$ & 32 \\
\hline $\mathrm{L}(\mathrm{mm})$ & 82 \\
\hline $\mathrm{h}_{\mathrm{b}}(\mathrm{mm})$ & 4 \\
\hline $\mathrm{l}_{\mathrm{c}}(\mathrm{mm})$ & 1.5 \\
\hline $\mathrm{l}_{\mathrm{a}}(\mathrm{mm})$ & 1 \\
\hline $\mathrm{H}(\mathrm{mm})$ & 36
\end{tabular}

A heat source (5) of dimensions $35 \times 35 \times 15 \mathrm{~mm}$, emitting a power of 80 Watt simulating the central processing unit, is fixed on the base of the heat sink and surrounded by an insulation to minimize thermal losses. A thermal grease was applied to ensure better thermal conductivity between the heat source and the heat sink (FIG. 3). The jet of air is placed above the heat sink, at blowing heights whose variation will have a notable influence on the velocity of air flow.

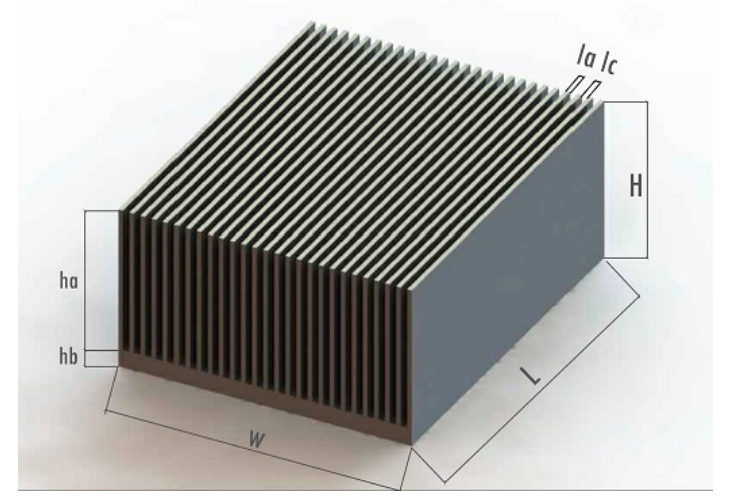

Figure 2. Rectangular minichannel plate fin heat sink

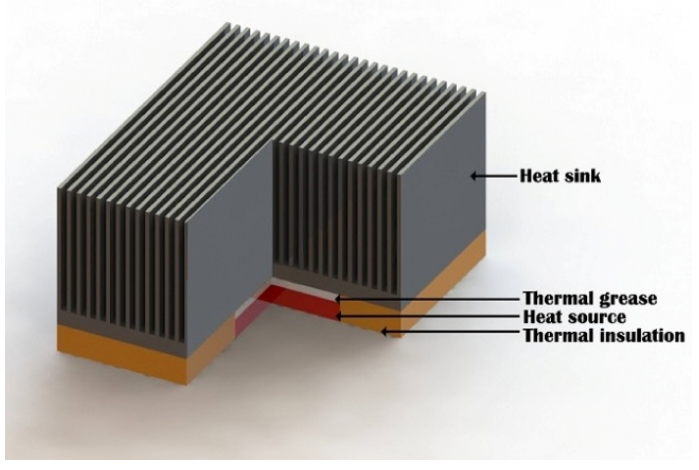

Figure 3. Fixing of the heat source on the heat sink 


\section{EXPERIMENTAL METHODOLOGIES}

The air flow temperatures and those through the heat sink are measured with an accuracy of $\pm 0.4 \%$ using thermocouples (see Fig 1) of type $\mathrm{K} \varnothing 0.2 \mathrm{~mm}$, connected to a digital thermometer (6). The flow velocity is measured along the air/heat sink impinging surface with a hot wire anemometer probe moving perpendicular to the channel axis of the heat sink (7) displaying an accuracy of $\pm 0.3 \%$. The pressure drops across the heat sink, $\Delta \mathrm{p}=\mathrm{p}_{\mathrm{in}}-\mathrm{p}_{\text {out }}$, is measured by two pressure taps, one at the inlet and the other at the heat sink outlet, connected to a differential pressure gauge with digital display (8), the precision of which is evaluated to $\pm 0.5 \%$. Several mean velocities of blowing, ranging from $0.5 \mathrm{~m} / \mathrm{s}$ to $5 \mathrm{~m} / \mathrm{s}$, under a laminar flow regime in the channels of the heat sink, are indeed adopted. The flow regime is defined by the Reynolds number as follows:

$$
\mathrm{R}_{\mathrm{e}}=\frac{U D_{h}}{v}
$$

where: $D_{h}=\frac{4 A}{P_{m}}=\frac{2 h_{a} l_{c}}{h_{a}+l_{c}}$

where $\mathrm{A}$ is the exchange surface between two adjacent fins.

At steady state, the thermal balance between the heat sink and the external environment is expressed as follows:

$$
Q_{\text {elec }}=Q_{\text {conv }}+Q_{\text {rad }}+Q_{\text {loss }}
$$

$Q_{\text {elec }}$ is the total electrical power applied at the base of the heat sink, $Q_{\text {conv }}, Q_{\text {rad }}$, Qloss are the heat transfer flows of the heat sink by convection, radiation and conduction heat losses, respectively.

The radiative heat power $Q_{r a d}$, is given as follows [20]:

$$
Q_{\text {rad }}=\sigma F A_{s}\left(T^{4}{ }_{w}-T^{4}{ }_{a}\right)
$$

Since the fins and base of the heat sink are made of highly polished aluminum to reduce their emissivity, $Q_{\text {rad }}$ will be neglected in what follows.

Thermal losses by $Q_{\text {loss }}$ conduction are minimized by the good insulation of the heat source and the base of the heat sink. According to [21], we write:

$$
\text { Qloss }=\frac{\text { AKins }}{\Delta X} \text { Tins }
$$

where $\mathrm{A}$ is the base surface of the heat sink, $\mathrm{K}_{\mathrm{ins}}$ is the thermal conductivity of the insulation, $\Delta \mathrm{T}_{\text {ins }}$ is the temperature difference across the insulation and $\Delta \mathrm{X}$ is the thickness of the insulation.

The convective heat transfer coefficient $h$ is calculated according to [22] as follows:

$h=\frac{Q \text { conv }}{A t\left[T_{j}-T_{j e t}\right]}=\frac{\text { Qelec }- \text { Qloss }}{A t\left[T_{j}-T_{j e t}\right]}$

With: $\mathrm{T}_{\mathrm{jet}} \approx \mathrm{T}_{\mathrm{amb}}$ and $\mathrm{A}_{\mathrm{t}}$ is the heat exchange surface, given according to $[23 ; 24]$ by the relation:

$$
A_{t}=N A_{f}+A_{b}
$$

The thermal resistance is calculated by the following relation:

$A t=\frac{T j-T j e t}{\text { Qelec }- \text { Qloss }}$

\section{RESULTS AND DISCUSSIONS}

\section{1 influence of the height of the impinging jet on the velocity profile}

The velocity of the jet in the considered cooling system is low in the central zone of the duct. This is due to the passive area of the axial fan motor, thus causing a low cooling zone [25]. This zone of low air jet corresponds to the hottest zone on the heat sink [26]. It is noted that the passive surface of the axial fan wheel occupies $20 \%$ of the input surface of the impact air jet (Figure 4). On the basis of which is setting the heat source which is thermally insulated from the external environment. To evacuate the maximum heat through the channels of the heat sink, by improving the flow of air in the zone at low velocity, the Y/D ratio is varied. For the present study, three impact air jet heights are considered: $\mathrm{Y} / \mathrm{D}=0.303$, $\mathrm{Y} / \mathrm{D}=0.606, \mathrm{Y} / \mathrm{D}=0.909$. figure5 $\mathrm{a}, \mathrm{b}, \mathrm{c}$ illustrates the velocity profiles of the impact air jet for the different jet heights., for a constant operating velocity of the axial fan, it can be seen that for a constant operating speed of the axial fan, when approaching the central impact zone, the speed of the air jet decreases.

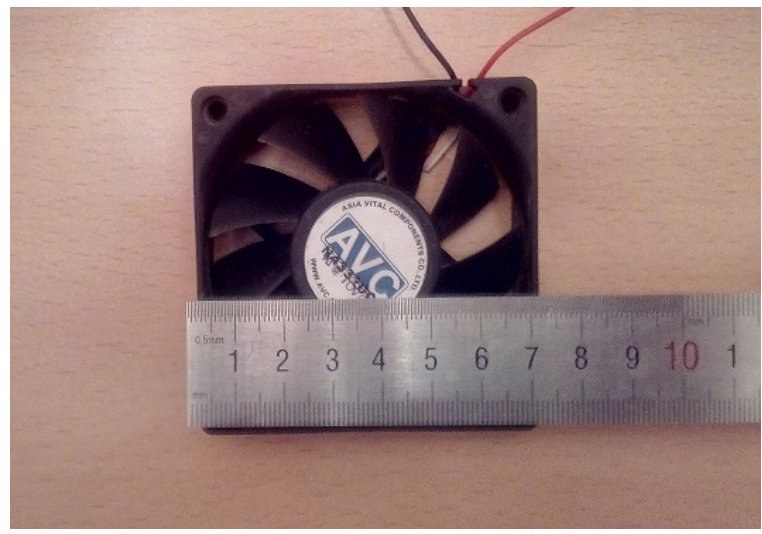

Figure 4. Axial fan

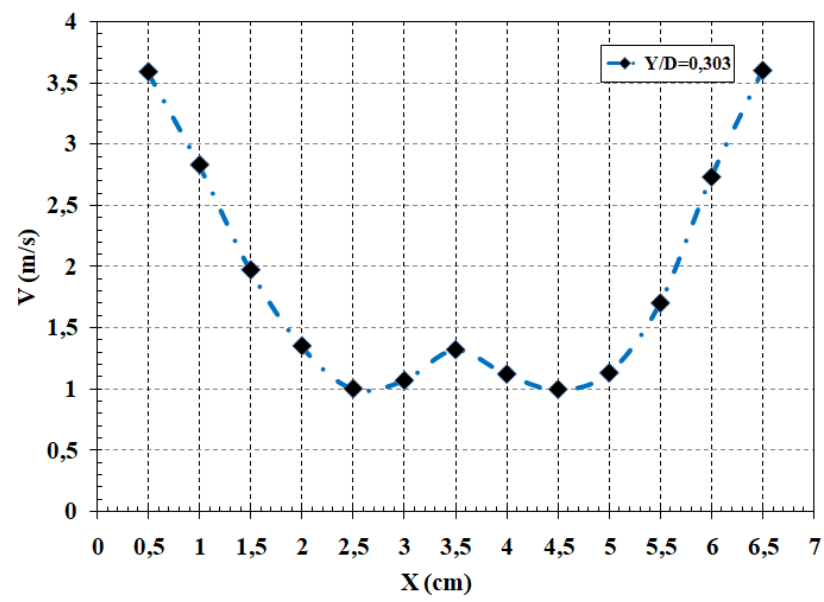

(a) $\mathrm{Y} / \mathrm{D}=0.303$ 


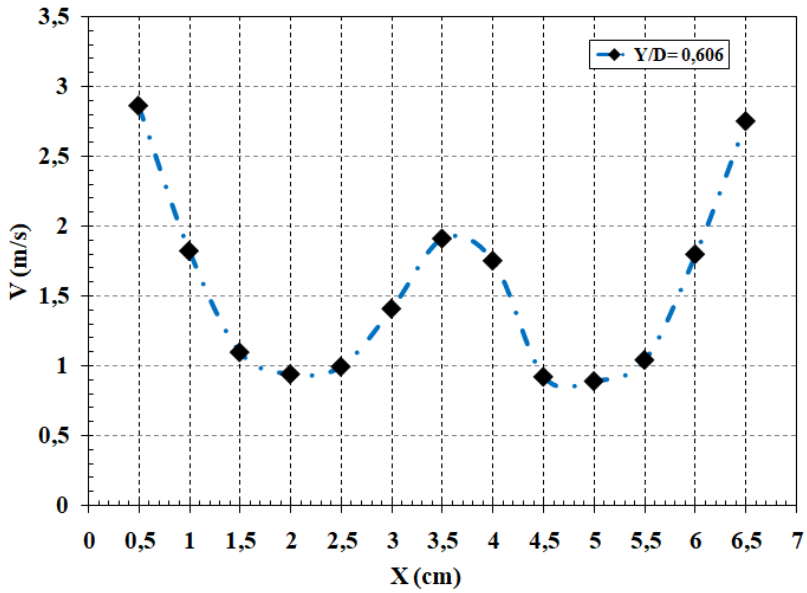

(b) $\mathrm{Y} / \mathrm{D}=0.606$

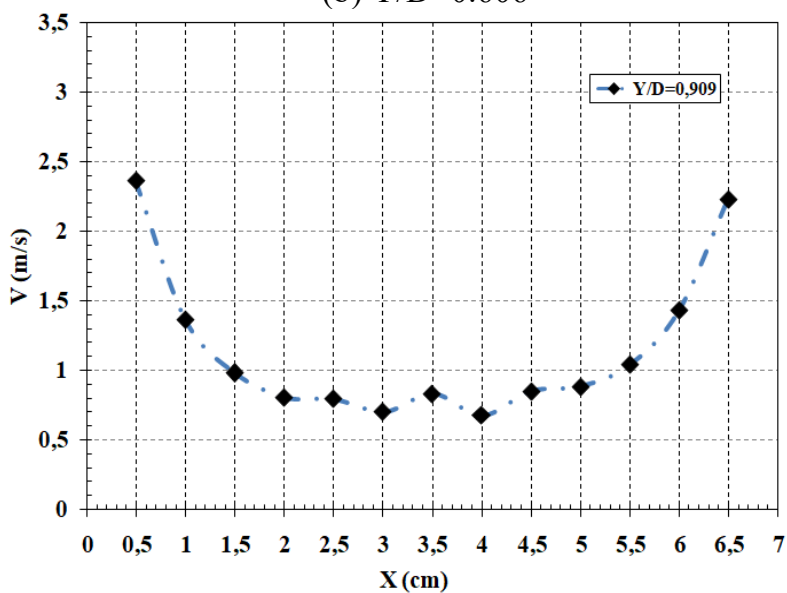

(c) $\mathrm{Y} / \mathrm{D}=0.909$

Figure 4. Influence of the height impinging jet on the velocity profile

\subsection{Influence of the height of the impinging jet on the junction temperature}

Figure 5. a,b,c illustrates the change in the case temperature between the heat source and the base of the heat sink as a function of the mean jet velocity for different $Y / D$ ratios. The case temperature Tcase decreases with a substantially linear appearance when the velocity of the jet increases. When the velocity of the jet reaches $3.5 \mathrm{~m} / \mathrm{s}$, the flow regime being laminar $(\mathrm{Re}=640)$, the junction temperature takes a linear form with a slight slope.

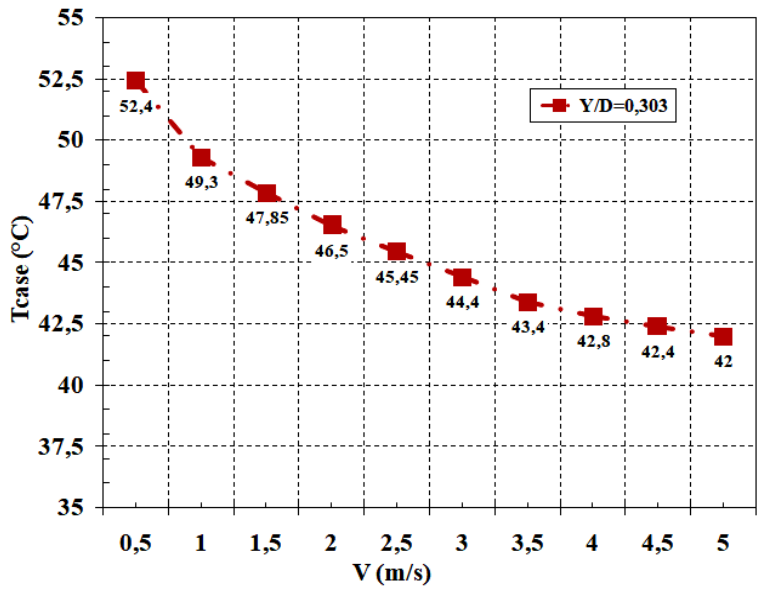

(a)

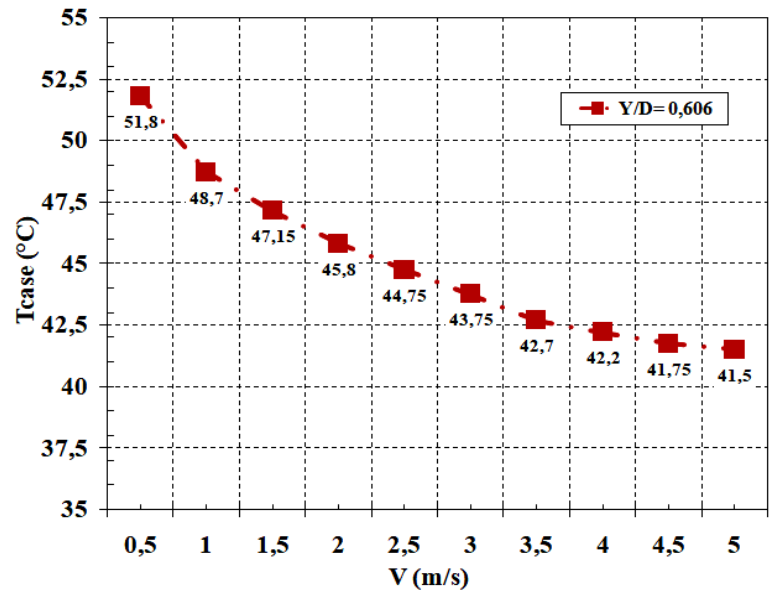

(b)

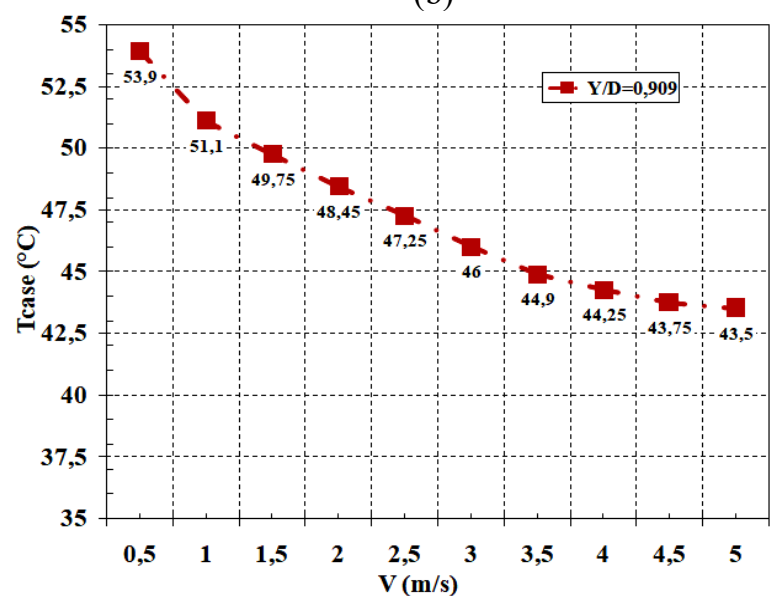

(c)

Figure 5. Junction temperature versus the jet velocity

As for the influence of the jet height on Tcase, it can be seen that the case temperature assumes higher values for $\mathrm{Y} / \mathrm{D}$ ratios greater than 0.606. This is also true for ratios below 0.606 , which could be explained by the fact that the spacing between the jet and the heat sink becomes confined, thus preventing the jet to flourish sufficiently to ensure to the heat sink better cooling. By making a connection between figures 4 and 5, it can be deduced that the $\mathrm{Y} / \mathrm{D}=0.606$ station offers better cooling to the central processing unit than all the other stations.

\subsection{Influence of the height of the jet impinging on the thermal resistance}

The variation of the impact distance affects not only the velocity of the jet but also the range of the jet in the heat sink. To study the influence of the impact distance (Y / D) on the thermal resistance, reconsider the three heights (stations) of jet, where the velocity of the jet of air varies from $1.5 \mathrm{~m} / \mathrm{s}$ to $4 \mathrm{~m} / \mathrm{s}$. The results are shown in Figures 6.a, b, c.

Indeed, we see that the thermal resistance increases if the impact distance $\mathrm{Y} / \mathrm{D}$ is too long or too short. The results indicate that the thermal resistance obviously decreases with an increase in the Y/D. On the other hand, it increases with $\mathrm{Y} / \mathrm{D}$. It turns out that the ratio $\mathrm{Y} / \mathrm{D}=0.606$ is the most suitable for effective reduction of the thermal resistance. 


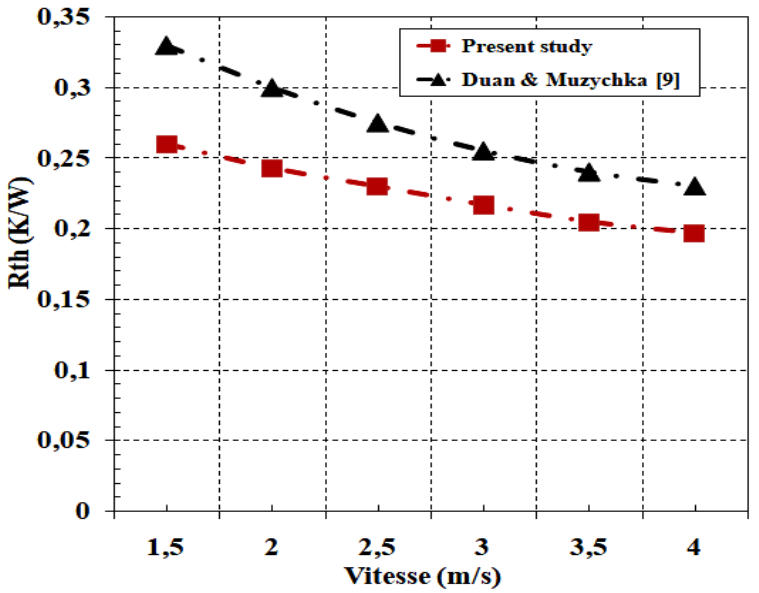

(a) $\mathrm{Y} / \mathrm{D}=0.303$

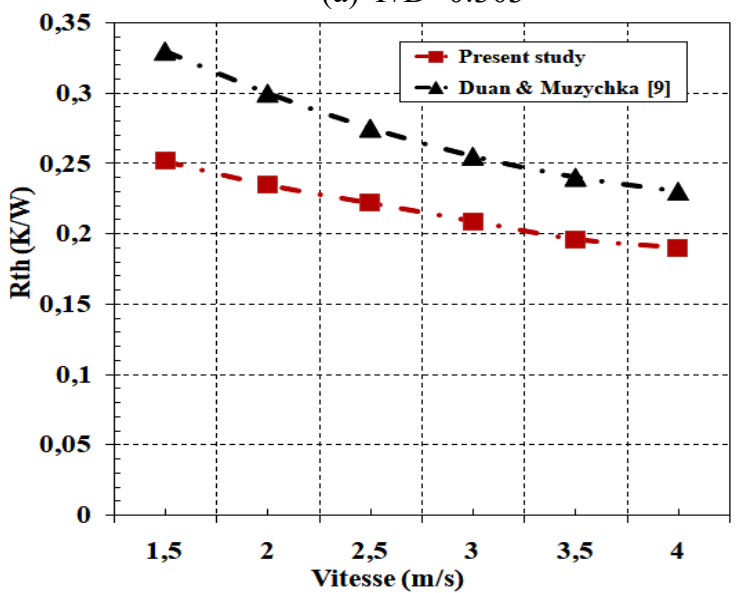

(b) $\mathrm{Y} / \mathrm{D}=0.606$

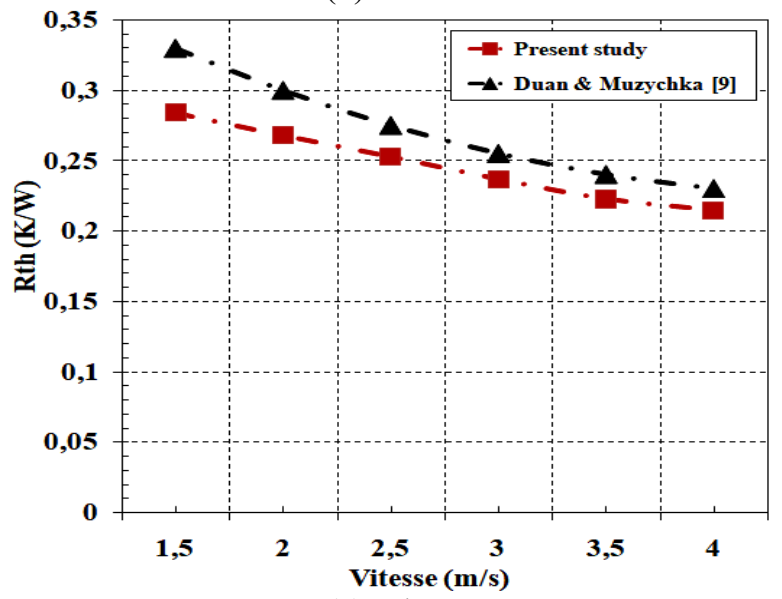

(c) $\mathrm{Y} / \mathrm{D}=0.909$

Figure 6. Thermal resistance as a function of jet velocity

If the jet height is too short, the impact distance of the jet is limited, which minimizes the heat exchange between the jet and the heat sink. If now the impact distance is too long, the jet may not be able to effectively penetrate the inter-fin space to evacuate the heat.

Figure 6 also shows the evolution of the thermal resistance as a function of the average velocity of the jet. It can be seen that as the velocity of the jet increases, the thermal resistance decreases, first with a steeper slope up to a velocity of $3.5 \mathrm{~m} / \mathrm{s}$ where it becomes practically insensitive to the velocity of the jet. This decrease in thermal resistance as the velocity of the jet increases, shows the increase in heat dissipation. This result is comparable to the results obtained experimentally by Duan and Muzychka [9], by the difference found between the two results is due probably to the difference which exists between the configurations of the heat sink used.

\subsection{Evolution of pressure drop through the heat sink channel as a function of jet velocity}

The pressure drop $\Delta \mathrm{P}$, which is the other aerodynamic performance of the heat sink, is measured for the optimal jet height of $40 \mathrm{~mm}(\mathrm{Y} / \mathrm{D}=0.606)$, as a function of the mean air jet velocity. According to figure7, the pressure drop increase gradually to a speed of $3.5 \mathrm{~m} / \mathrm{s}$, where they maintain the same slope. This result is comparable to the result obtained by Duan and Muzychka [10]. We deduce that the jet velocity when taking larger values favors the increase of the pressure drop especially above the jet velocities exceeding $3.5 \mathrm{~m} / \mathrm{s}$ as illustrated in the figure 7.

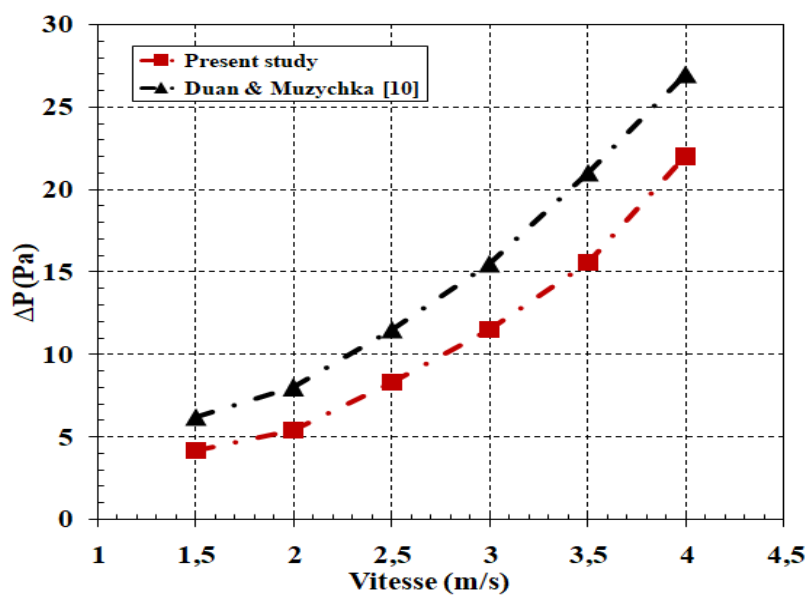

Figure 7. Pressure drop in the heat sink channel as a function of jet velocity

\subsection{Optimal cooling system operation point}

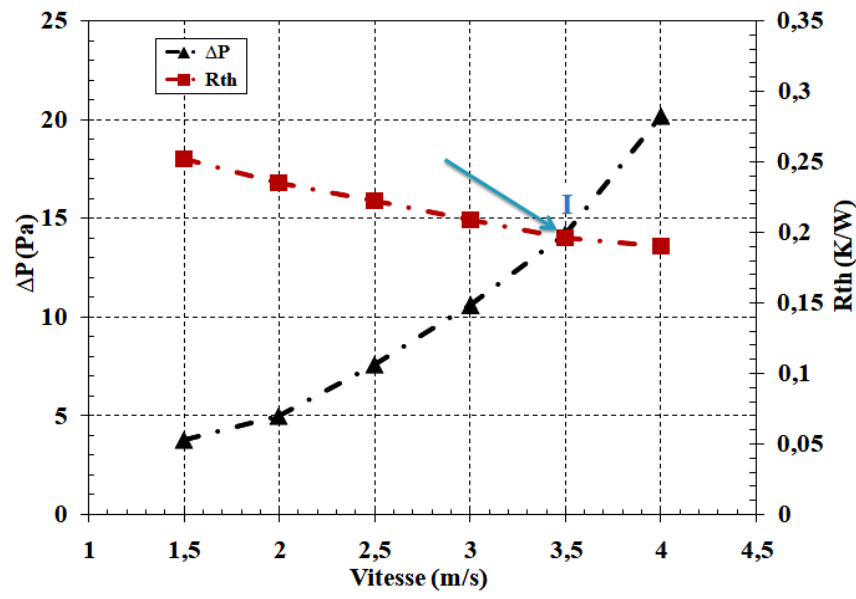

Figure 8. Optimal operating point of the cooling system.

In figure 8 we have superimposed the curves of the two thermal and aerodynamic performances in the aim to find a common point that takes into account both thermal and aerodynamic characteristics, to draw the optimal cooling rate of cooling. The increase in the jet velocity induces the decrease of the heat resistance of the heat sink, which is highly sought after. On the other hand, the recorded pressure drop increases to the point (I) for a common blowing velocity $\mathrm{V}_{\mathrm{I}}$, close to 3.5 $\mathrm{m} / \mathrm{s}$. This common point $\mathrm{I}$, which can be taken an operating 
point, was a compromise given optimal performance to the cooling system. Thus, this velocity which returns each time has just been confirmed once again by the result of figure 8 . It can be considered as the optimal jet velocity required. It allows efficient cooling with a pressure drop corresponding to a lowest possible thermal resistance. These results given better cooling with less energy consumption and even less nuisance noise

\subsection{Influence of the position of the heat source on the junction temperature}

Successfully achieving the overall design of the central processing unit cooling system means achieving a high heat transfer rate at minimum energy cost. The influence of the positioning of the heat source (CPU) bonded to the base of the heat sink, on the junction temperature $\mathrm{Tj}$, seems to meet the challenge. Indeed, consider three axes, transversal, longitudinal, and diagonal, along which, the source will undergo displacements with constant pitch of $5 \mathrm{~mm}$. The diagram shown in figure 10 illustrates the different positions reached by the heat source from its initial (central) position $\mathrm{C}$. Three positions are in fact studied on each of the axes without counting the central position (Tjc).

Figure 9 shows the influence of the position of the heat source along the three aforementioned axes on the evolution of the junction temperature as a function of the speed of the impacting jet.

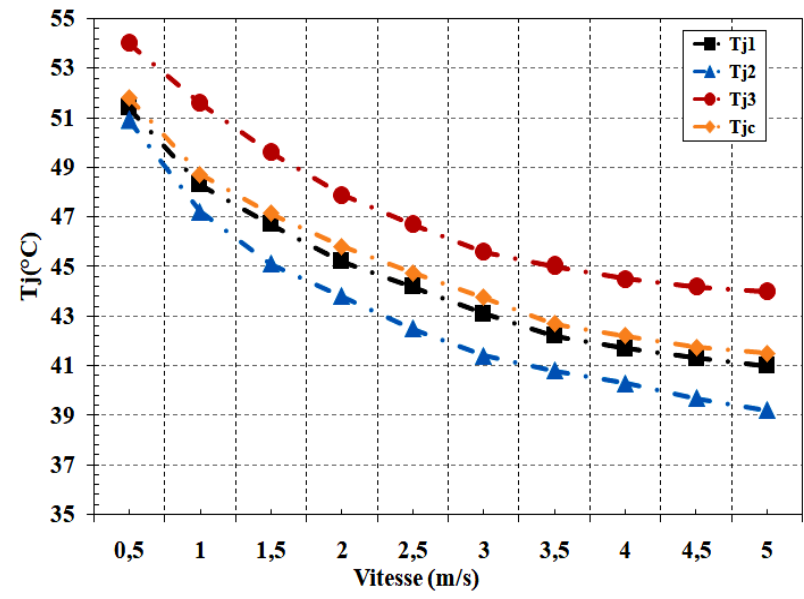

a)

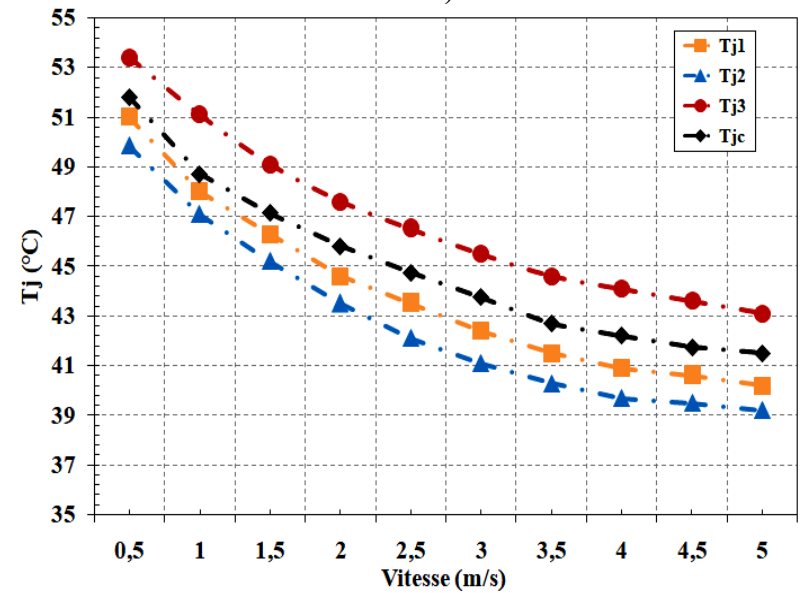

b)

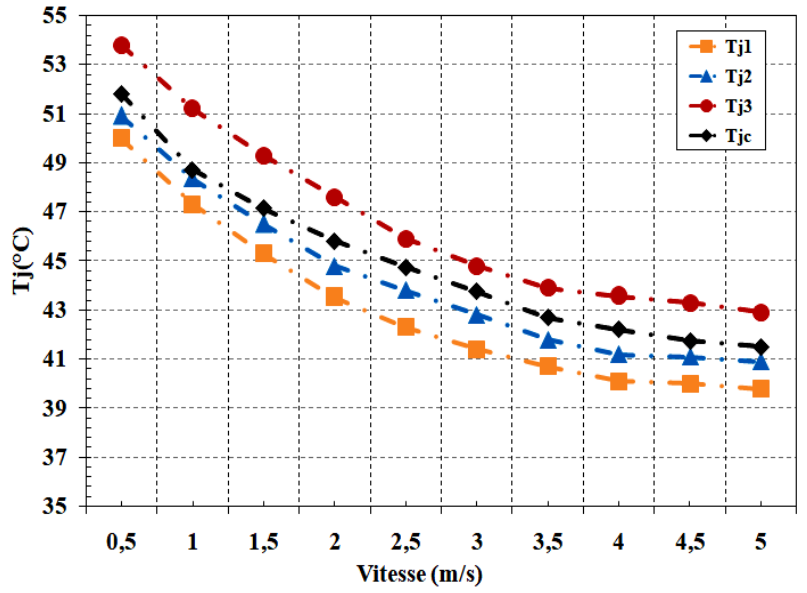

c)

Figure 9. Influence of the position of the heat source on the junction temperature (a) on the transverse axis (b) on the longitudinal axis

(c) on the diagonal axis

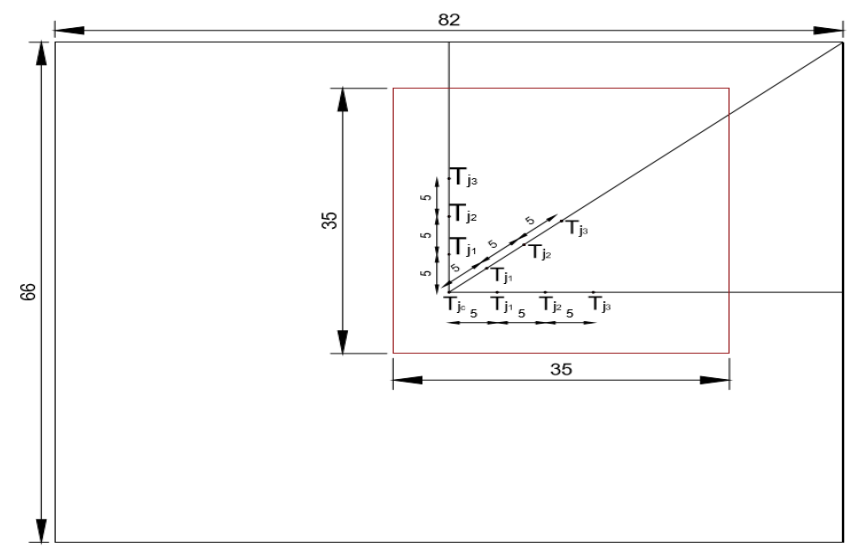

Figure 10. Displacement of the heat source

The displacement of the heat source from the center of the base of the heat sink seems to have a significant influence on the junction temperature. So there are three different displacements, Transversal (Figure 9.a), longitudinal (Figure 9.b) and Diagonal (Figure 9.c). Longitudinally, it is observed that the junction temperature is reduced by $6 \%$ with respect to the transverse case, while noting that the second position (Tj2) of the heat source is always preferred as regards the junction temperature the lowest relative to the initial position. With respect to the diagonal displacement, the position which offers the lowest temperature is the first position (Tj1).

In the light of the results obtained above, Fig. 11 shows, the rates of improvement of the junction temperature, resulting from the different directions of displacement of the heat source with respect to its initial position (Tjc). It is found that the longitudinal displacement of the heat source offers the best reduction in the junction temperature, evaluated by a rate of $10 \%$ under the optimal blowing conditions, compared with the industrial case where the height of the jet is almost negligible. 


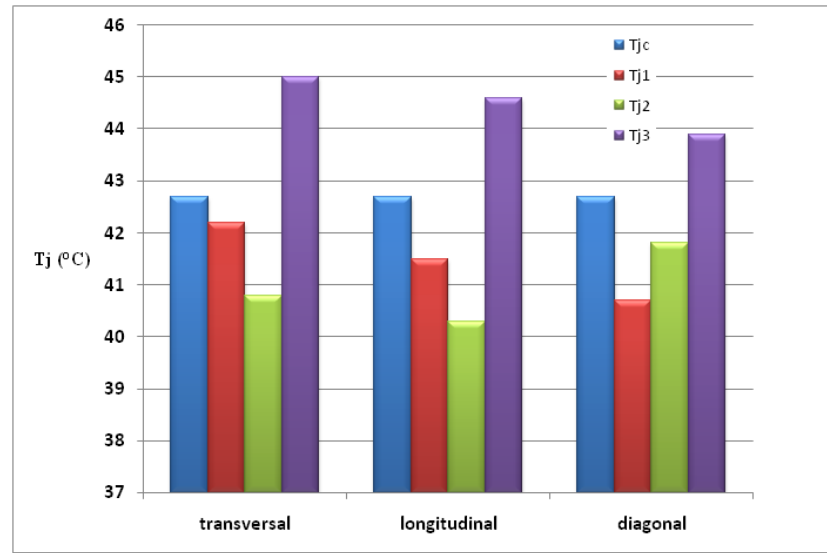

Figure 11. Comparison of the junction temperatures

Moreover, the coefficient of heat transfer by convection represents an important parameter in the cooling of the heat sink. Indeed, Fig. 12 shows the evolution of the coefficient of convective heat transfer for two positions of the heat source. The first position (hc) is at the center of the base of the heat sink and the second position is the optimal position (cf Fig 9) along the longitudinal axis (h-opt). It can be seen that the displacement of the heat source on the longitudinal axis for a pitch of $10 \mathrm{~mm}$ from the central position provides more efficient convective heat transfer.

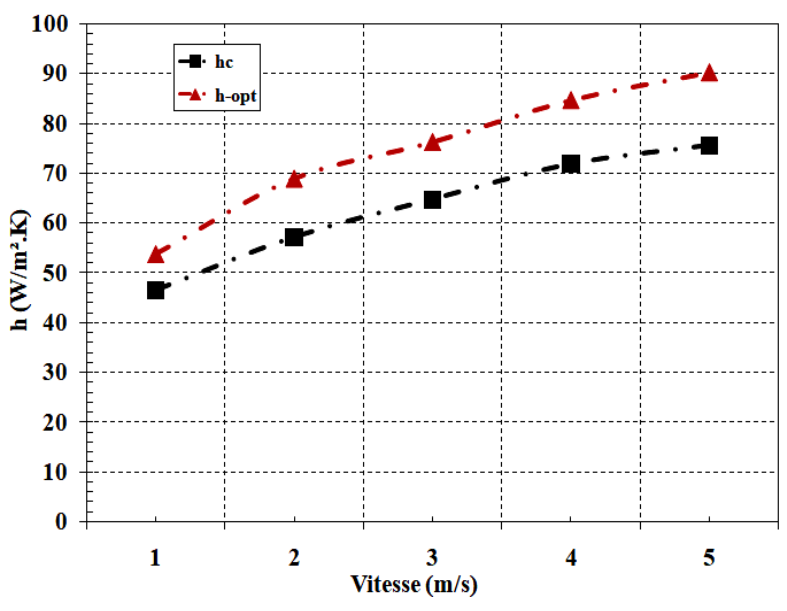

Figure 12. Heat transfer coefficient

\section{CONCLUSION}

The experimental study carried out in this work was devoted to the cooling of the desktop central processing unit by means of a heat sink with rectangular plate fins, subjected to an air impinging jet. The variable jet height $\mathrm{Y}$ is an important parameter in the performance characterization of heat sinks. For this, a series of experimental measurements was carried out under the influence of the Y/D ratio. From the results obtained, the following conclusions can be drawn: The dimensionless ratio $\mathrm{Y} / \mathrm{D}=0.606$ corresponding to the height of the jet $Y=40 \mathrm{~mm}$, offers better cooling performance on the heat sink. Therefore, the need to find a compromise by superimposing the characteristics of the two thermal performances (Rth) and aerodynamics $(\Delta \mathrm{p})$ of the heat sink made it possible to conclude that $3.5 \mathrm{~m} / \mathrm{s}$ is the velocity of the jet which ensures Optimal cooling of the central processing unit. It should also be noted that the position of the heat source (central processing unit) on the base of the heat sink, relative to the initial position, was a very important parameter of influence, which also required special attention. This led to a series of measures. It is found that the position of the heat source on the longitudinal axis at $10 \mathrm{~mm}$ from the center of the base of the heat sink provides better heat dissipation through the heat sink, characterized by a $10 \%$ decrease in the junction temperature. The results obtained will be of benefit to manufacturers in improving the cooling conditions of desktop CPUs.

\section{REFERENCES}

[1] Li HY, Chen CL, Chao SM, Liang GF. (2013). Enhancing heat transfer in a plate-fin heat sink using delta winglet vortex generators. International Journal of Heat and Mass Transfer 67: 666-677. https://doi.org/10.1016/j.ijheatmasstransfer.2013.08.042

[2] Huang CH, Chen YH. (2013). An impingement heat sink module design problem in determining optimal nonuniform fin widths. International Journal of Heat and Mass Transfer 67: 992-1006. https://doi.org/10.1016/j.ijheatmasstransfer.2013.08.103

[3] Brignoni LA, Garimella SV. (1999). Experimental optimization of confined air jet impingement on a pin-fin heat sink. IEEE Trans. Compon. Pack. Technol 22: 399404. https://doi.org/10.1109/6144.796542

[4] El-Sheikh HA, Garimella SV. (2000). Enhancement of air impingement heat transfer using pin-fin heat sinks. IEEE Trans. Compon. Pack. Technol. 23(2): 300-328. https://doi.org/10.1109/6144.846768

[5] Maveety JG, Hendricks JG. (1999). A heat sink performance study considering material, geometry. Reynolds number with air impingement. J. Electron. Packag 121: 156-161. https://doi.org/10.1115/1.2792678

[6] Maveety JG, Jung HH. (2002). Heat transfer from square pin-fin heat sinks using air impingement cooling. IEEE Trans. Compon. Pack. Technol. 25: 459-469. https://doi.org/10.1109/TCAPT.2002.803650

[7] Biber CR, Fijol S. (1999). Fan-plus-heatsink optimization- mechanical and thermal design with reality. Proceedings of the International Systems Packaging Symposium 285-289.

[8] Sathe SB, Sammakia BG. (2004). An analytical study of the optimized performance of an impingement heat sink. J. Electron. Packaging 126: 528-534. https://doi.org/10.1115/1.1827269

[9] Duan ZP, Muzychka YS. (2004). Impingement air cooled plate fin heat sinks Part II- Thermal resistance model. Proceedings of 9th Int. Soc. Conf. Therm. Phnom. Electronic Syst 36-443: https://doi.org/10.1109/ITHERM.2004.1319207

[10] Duan ZP, Muzychka YS. (2004). Impingement air cooled plate fin heat sinks Part I-pressure drop model. Proceedings of 9th Int. Soc. Conf. Therm. Phenom. Electronic Syst 429-435. https://doi.org/10.1109/ITHERM.2004.1319206

[11] Li HY, Chen KY. (2007). Thermal performance of platefin heat sinks under confined impinging jet conditions. International Journal of Heat and Mass Transfer 50: 1963-1970.

https://doi.org/10.1016/j.ijheatmasstransfer.2006.09.024 
[12] Li HY, Chen KY, Chiang MH. (2009). Thermal-fluid characteristics of plate-fin heat sinks cooled by impingement jet. Energy Conversion and Management 50: $2738-2746$ https://doi.org/10.1016/j.enconman.2009.06.030

[13] Li HY, Chao SM, Tsai GL. (2005). Thermal performance measurement of heat sinks with confined impinging jet by infrared thermography. International Journal of Heat and Mass Transfer 48: 5386-5394. https://doi.org/10.1016/j.ijheatmasstransfer.2005.07.007

[14] Kim DK, Kim JK, Bae JK. (2009). Comparison of thermal performances of plate-fin and pin-fin heat sinks subject to an impinging flow. International Journal of Heat and Mass Transfer 52: 3510-3517. https://doi.org/10.1016/j.ijheatmasstransfer.2009.02.041

[15] Diani A, Mancin S, Zilio C, Rossetto L. (2013). An assessment on air forced convection on extended surfaces. Experimental results and numerical modeling. International Journal of Thermal Sciences 67: 120-134. https://doi.org/10.1016/j.ijthermalsci.2012.11.012

[16] Mesalhy OM, El-Sayed MM. (2015). Thermal performance of plate fin heat sink cooled by air slot impinging jet with different cross sectional area. Heat Mass $\quad$ Transfer $\quad 51$ 8 $899-899$ https://doi.org/10.1007/s00231-014-1463-5

[17] Camaraza-Medina Y, Rubio-Gonzales ÁM, CruzFonticiella OM, García-Morales OF. (2018). Simplified analysis of heat transfer through a finned tube bundle in air cooled condenser. Mathematical Modelling of Engineering Problems 5(3): 237-242. https://doi.org/10.18280/mmep.050316

[18] Camaraza-Medina Y, Khandy NH, Carlson KM, Cruz Fonticiella OM, García-Morales OF, Reyes-Cabrera D. (2018). Evaluation of condensation heat transfer in aircooled condenser by dominant flow criteria. Mathematical Modelling of Engineering Problems 5(2): 76-82. https://doi.org/10.18280/mmep.050204

[19] HoSung L. (2011). Thermal design. John Wiley \& Sons, Inc.

[20] Naik S, Probert SD, Shilston MJ. (1987). Forcedconvective steady-state heat transfers from shrouded vertical fin arrays, aligned parallel to an undisturbed airstream. Appl. Energy 26(2): 137-158 https://doi.org/10.1016/0306-2619(87)90015-8

[21] Al-Damook A, Kapur N, Summers JL, Thompson HM. (2015). An experimental and computational investigation of thermal air flows through perforated pin heat sinks. Applied Thermal Engineering 89: 365-376. https://doi.org/10.1016/j.applthermaleng.2015.06.036

[22] Holman JP. (2011). Experimental methods for engineers eighth ed., McGraw Hill Book Company.

[23] Incropera. (2007). Dewitt, Bergman, and Lavine., Fundamentals of Heat and Mass Transfer, 6th ed.

[24] Taji SG, Parishwad GV, Sane NK. (2014). Enhanced performance of horizontal rectangular fin array heat sink using assisting mode of mixed convection. International Journal of Heat and Mass Transfer 72: 250-25. https://doi.org/10.1016/j.ijheatmasstransfer.2014.01.012

[25] Beriache M, Bettahar A, Loukarfi L. (2012). Fluid flow and thermal characteristics of a minichannel heat sink with impinging air flow. Arab J Sci Eng 37: 2243-2254. https://doi.org/10.1007/s13369-012-0321-3

[26] Belarbi AA, Beriache M, Bettahar A. (2015). Caractérisation expérimentale des performances d'un dissipateur de chaleur à mini-canaux. Proceedings du Congrès Français de Thermique, La Rochelle, France, p. 13.

\section{NOMENCLATURE}

$A_{t}: \quad$ Heat exchange surface, $\mathrm{mm}^{2}$

$A_{f}: \quad$ Surface of the fin, $\mathrm{mm}^{2}$

$A_{\mathrm{b}}$ : $\quad$ Surface inter-fins, $\mathrm{mm}^{2}$

$D_{h}$ : $\quad$ Hydraulic diameter, $m m$

$D: \quad$ jet diameter, $m m$

$H$ : $\quad$ Heat sink height, $m m$

$h$ : $\quad$ Convection heat transfer coefficient, $W \cdot m^{-2} \cdot K^{-1}$

$h_{a}: \quad$ fin height, $\mathrm{mm}$

$h_{b}$ : Thickness of heat sink base, $\mathrm{mm}$

$L$ : $\quad$ Length of fin, $\mathrm{mm}$

$l_{a}: \quad$ Thickness of the fin, $m m$

$l_{c}: \quad$ Channel width, $m m$

$N: \quad$ Number of fins

Pm: $\quad$ Wet perimeter, $\mathrm{mm}$

$Q_{\text {elec: }}$ Heat source power applied to the base of the heat sink, $W$

$Q_{\text {conv }}:$ Convection heat flow, $W$

$Q_{\text {rad }}: \quad$ Radiation heat flux, $W$

$Q_{\text {loss: }}: \quad$ Heatpower loss, $W$

$R_{t h}: \quad$ Thermal resistance, $K . W^{-1}$

$R e$ : Number of Reynolds

$S: \quad$ Inlet Width, mm

$t_{b}$ : $\quad$ Thickness of heat sink base, $\mathrm{mm}$

Tcase: case temperature of processor (heat source), ${ }^{\circ} \mathrm{C}$

$T_{a m b}: \quad$ Ambient temperature, ${ }^{\circ} \mathrm{C}$

$T_{\text {jet }}$ : $\quad$ Temperature of the impinging air jet, ${ }^{\circ} \mathrm{C}$

$U: \quad$ Mean jet velocity, $m \cdot s^{-1}$

$V: \quad$ Air jet velocity, $m . s$

$W: \quad$ heat sink width, $m m$

$X: \quad$ Transverse displacement of the probe

\section{Greek symbols}

$\begin{array}{ll}\Delta p: & \text { Pressure drop, } \mathrm{Pa} \\ v: & \text { Kinematic viscosity, } \mathrm{m}^{2} \cdot \mathrm{s}^{-1} \\ \rho: & \text { Density of fin material, } \mathrm{kg} \cdot \mathrm{m}^{-3}\end{array}$

